\title{
TISSUE COENZYME Q (UBIQUINONE) AND PROTEIN CONCENTRATIONS OVER THE LIFE SPAN OF THE LABORATORY RAT
}

ROBERT E. BEYER*, BONNIE-ANN BURNETT, KENNETH J. CARTWRIGHT, DEE W. EDINGTON ${ }^{\mathrm{a}}$, MICHAEL J. FALZON, KEVAN R. KREITMAN, THOMAS W. KUHN, BOBBI J. RAMP, STEPHEN YUNG SHIK RHEE, MITCHELL J. ROSENWASSER, MONA STEIN and LAWRENCE CHIN-I AN

Laboratory of Chemical Biology, Department of Cellular and Molecular Biology, Division of Biological Sciences, and ${ }^{a}$ Department of Kinesiology, Division of Physical Education, The University of Michigan, Ann Arbor, MI 48109-1048 (U.S.A.)

(Received April 23rd, 1985)

(Revision received July $3 \mathrm{rd}, 1985$ )

\section{SUMMARY}

The coenzyme $Q$ (ubiquinone) concentrations of a number of tissues have been determined over the life span of the male laboratory rat. Coenzyme $Q$ increased between 2 and 18 months and decreased significantly at 25 months in the heart and kidney, and the gastrocnemius, oblique and deep aspect (red) vastus lateralis muscles. The coenzyme $Q$ concentration of liver increased over the life span, while it remained relatively constant in brain, lung, and the superficial aspect (white) of the vastus lateralis muscle. Data are also included for organ weights and protein contents of tissues over the life span. The various roles of coenzyme $Q$ in cellular electron transfer and its regulation, energy conservation in oxidative phosphorylation, and its clinical efficacy in diseases of energy metabolism are discussed. It is hypothesized that coenzyme $\mathbf{Q}$ serves as a free radical quencher in the mitochondrion, a major site of free radical formation, in addition to its other roles in cellular energy metabolism, and that its cellular diminution may contribute to the loss of cellular function accompanying ageing.

Key words: Coenzyme Q; Ubiquinone; Ageing; Free radical theory of aging; Heart; Liver; Muscle

\section{INTRODUCTION}

A great deal of information has become available on the decline of energy metabolism during ageing [see Refs. 1 and 2 for reviews] since the original report of a decrease in the

*To whom correspondence and reprint requests should be addressed. 
efficiency of oxidative phosphorylation in mitochondria from aged rats [3]. For example, it has been demonstrated that the ability of cardiac and skeletal muscle to catalyze the beta-oxidation of fatty acids is diminished in the aged rat [4-6]. The concentrations of skeletal muscle myoglobin [7], flavin [6], carnitine [5] and myocardial cytochromes [8-10] also decreased with age.

Despite its role as an obligatory member of the mitochondrial electron transfer chain [11], its regulation of succinate dehydrogenase [12-15], NADH dehydrogenase [16,17] and cytochrome $b-c_{1}$ complex [18-20] activities, and its participation in energy conservation in the protonmotive $Q$ cycle [21-23], coenzyme $Q^{*}$ has received limited attention with respect to the ageing process $[33,34]$. Because of these central roles in energy metabolism, we have determined the concentration of coenzyme $Q$ in various tissues of the rat over its life span. The wet weights and protein contents of the tissues studied also are reported as these parameters were obtained for coenzyme $Q$ reference values.

\section{MATERIALS AND METHODS}

\section{Materials}

Materials used were crystalline bovine serum albumin, TES and coenzyme $Q_{10}$ from Sigma Chemical Company, and sodium borohydride from Ventron Chemical Company. All other reagents were of analytical grade.

\section{Animals}

All animals used were male Sprague-Dawley rats designated $\mathrm{Crl}$ : $\mathrm{COBS}^{(\mathrm{R})} \mathrm{CD}^{(\mathrm{R})}(\mathrm{SD})$, obtained from Charles River Breeding Laboratories. Rats in the 9-, 18- and 25-month-old groups were obtained as retired breeders at $8-10$ months of age. The rats were housed singly in the Animal Care Facility of the Division of Biological Sciences in a room segregated from other species on a $12 \mathrm{~h}$ light/dark cycle. All animals received Purina Laboratory Rat Chow and water ad libidum. In our colony of ageing rats, approximately $85 \%$ survive to 25 months of age. Animals which showed pathology or unexplained, severe weight loss were excluded from participation in these experiments in order to distinguish between effects of ageing and disease.

\footnotetext{
*We prefer the trivial term coenzyme $Q$ to ubiquinone as a more accurate descriptor of 2,3-dimethoxy5-methyl-6-multiprenyl-1,4-benzoquinone for the following reasons: (i) The term ubiquinone implies that the compound is ubiquitous [24]. It is not present in a number of organisms [25] including gram positive bacteria [26] and some fungi [27]. It is also not present in the methanogenic bacteria [28]; (ii) A coenzymic function for this benzoquinone, originally suggested by Green [29], has recently received considerable experimental support [30-32] by the isolation of mitochondrial coenzyme $Q$ apoproteins or binding proteins; and (iii) The objection to the use of the term coenzyme $Q$ on the basis that it may be confused by students of biochemistry with a coenzyme of Q-enzyme [25] is no longer valid since this term for amylo (1,4-1,6)-transglycolase is no longer used in modern texts of biochemistry. A survey of recent textbooks of biochemistry indicates that the designation coenzyme $Q$ is preferred.
} 


\section{Preparation of homogenates}

Animals were anaesthetized with sodium pentobarbital $(40 \mathrm{mg} / \mathrm{kg}$, i.p.), tissues removed and placed immediately in ice-cold isotonic medium [35] containing $50 \mathrm{mM}$ TES,

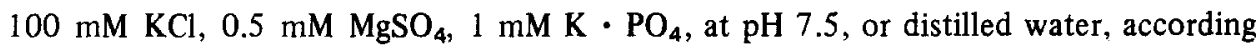
to their subsequent use. Respiratory movements ceased upon removal of the heart after which remaining tissues were removed rapidly. The tissues were rinsed until free of blood, blotted dry, freed of superficial connective tissue and fat, and then weighed to $\pm 1 \mathrm{mg}$. Tissues selected for analyses were heart (ventricles), liver, kidney, brain, lung, and gastrocnemius, soleus, internal + external oblique, and vastus lateralis muscles. The vastus lateralis muscles were separated into red deep region type IIA (DVL) and white superficial region type IIB (SVL) portions and the two analyzed separately. Tissues were analyzed immediately or stored frozen.

Immediately prior to analysis, a volume of cold deionized glass distilled water was added equal to 5 (heart and soleus muscle) or 2 (all other tissues) times the wet weight of the tissue. The tissue was minced and then homogenized for between 90 and $120 \mathrm{sec}$ with a Willem's Ultra-Turrax homogenizer (Model BEW, Janke and Kunkel, AB) operated at $60 \%$ of maximum speed. This procedure also removed the bulk of connective tissue.

\section{Assays}

Tissue protein concentrations were determined in triplicate by a biuret procedure [36] developed for analysis of fatty tissues from aged animals. Crystalline bovine serum albumin, used as standard, was prepared and standardized according to Kaziro et al. [37]. Tissue coenzyme $Q$ concentrations were analyzed in triplicate by the procedure of Kröger [38] with minor modifications. A molar extinction coefficient of $12.2 \mathrm{mM}^{-1} \cdot \mathrm{cm}^{-1}$ for oxidized minus reduced absorbancy at $275 \mathrm{~nm}$ was employed.

\section{Statistical analysis}

Data were analyzed by univariate one-way analysis of variance (ANOVA) using the Michigan Interactive Data Analysis System (MIDAS) developed by the staff of the Statistical Research Laboratory of The University of Michigan. Conservative post hoc Scheffe pairwise contrasts were then used to compare the groups.

\section{RESULTS}

The body weights of the animals used in this study are shown in Fig. 1. This strain (Sprague-Dawley) of laboratory rat continues to gain weight until about 18 months after which weight accrues at a lower rate. The weight attainment of the 25 -month-old rats shown in Fig. 1 is in agreement with previously published values from this laboratory [6,7].

The wet weights of the intact tissues and organs used in this study over the life span are listed in Table I. The weights of the heart, liver, brain and gastrocnemius and soleus 
BODY WEIGHT VS AGE, MALE S-D RATS

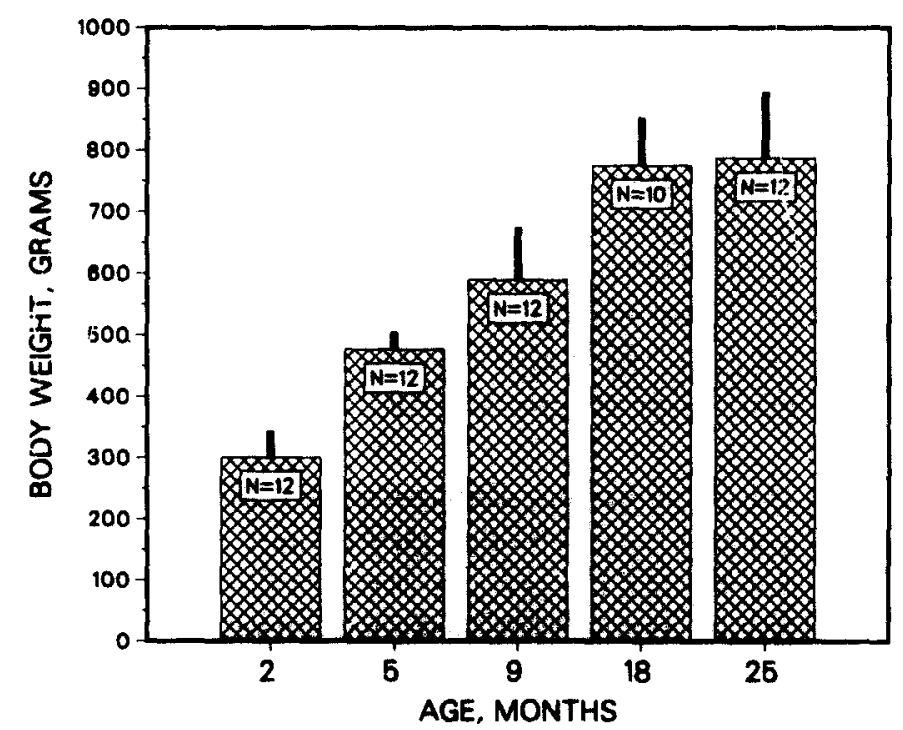

Fig. 1. Body weight vs. age, Sprague-Dawley male rats. $N=$ number of animals in each age group. Striped bars represent body weight; solid bars represent 1 standard deviation.

muscles increased between 2 and 18 months and then decreased slightly while the kidneys and lung continue to gain mass in old age. The continual increase in the weight of the lung in aged animals is consistent with an accumulation of elastin with age [39]. The group differences with respect to independent variables were highly significant for all of the organs measured (Table I).

The protein contents of the organs and intact muscles from 2 to 25 months are reported in Table II. With the exception of the brain in which protein content remained constant after 2 months of age, the protein content of the remainder of the tissues followed the pattern of changes in wet weight (Table I). This is reflected in the group differences significance values reported in Table II.

The coenzyme $\mathrm{Q}$ concentrations of tissues, calculated on a basis of tissue wet weight and including tissues for which samples instead of the entire tissue were taken, appear in Table III. Cardiac ventricular tissue, kidney, and gastrocnemius, deep vastus lateralis and soleus muscles all showed coenzyme $Q$ concentration increases to 18 months followed by dramatic declines in these tissues from aged animals. Lung and brain coenzyme $Q$, referred to tissue wet weight, remained relatively constant throughout the life span.

Tissue and organ coenzyme $Q$ concentrations calculated on a protein basis over the life span are reported in Table IV. Coenzyme $Q$ concentration increased in cardiac and kidney tissues and gastrocnemius, oblique and deep vastus lateralis muscles to 18 months, followed by a decline in the aged, 25-month-old rat. The coenzyme $Q$ concentrations of 


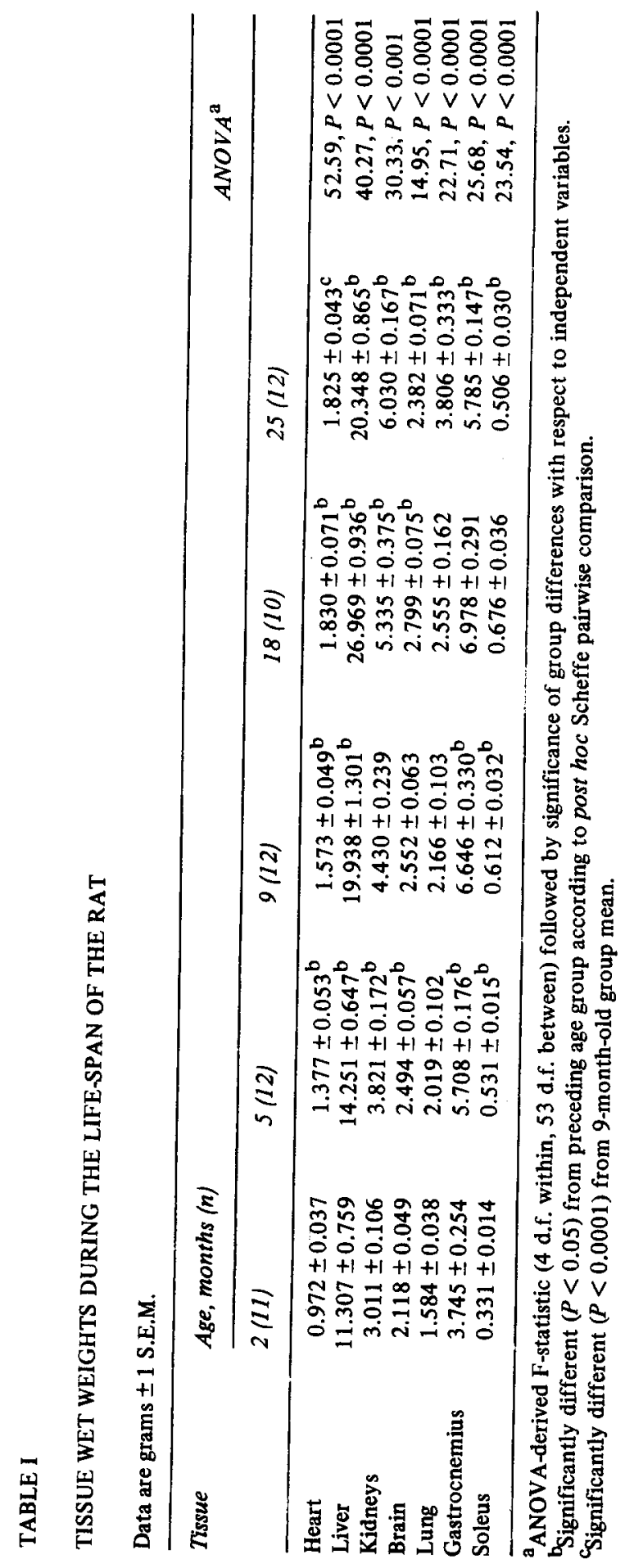




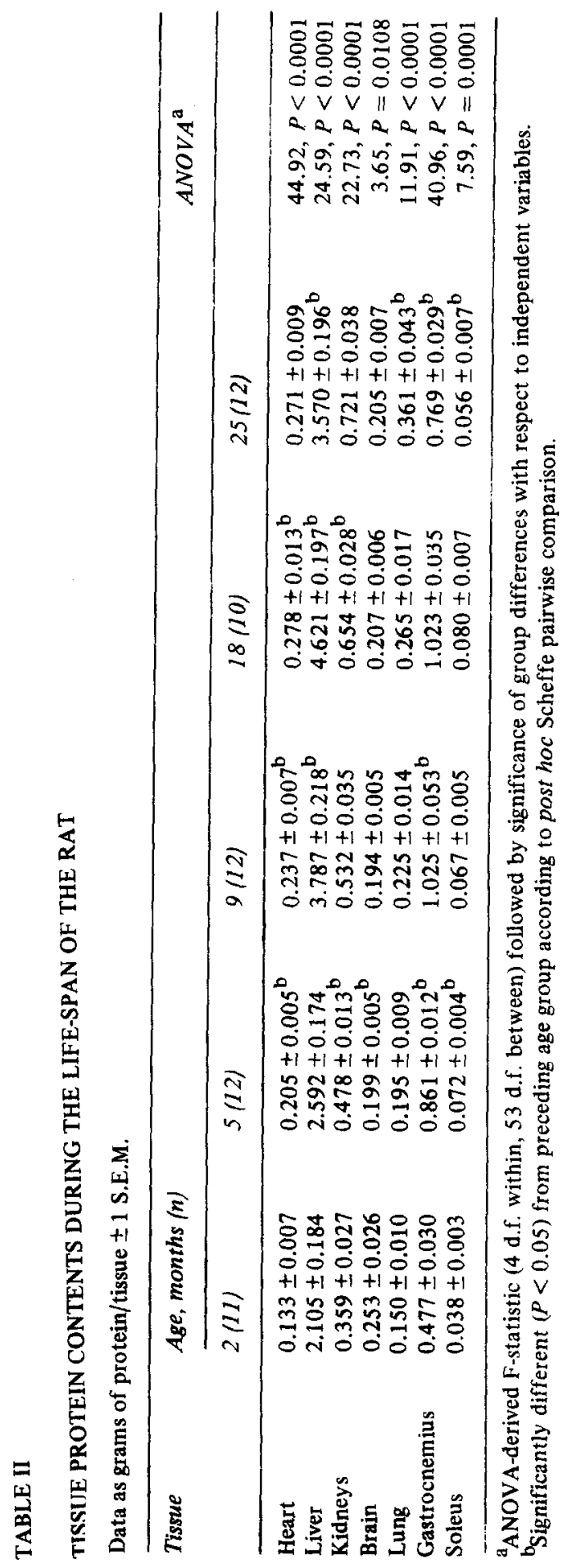




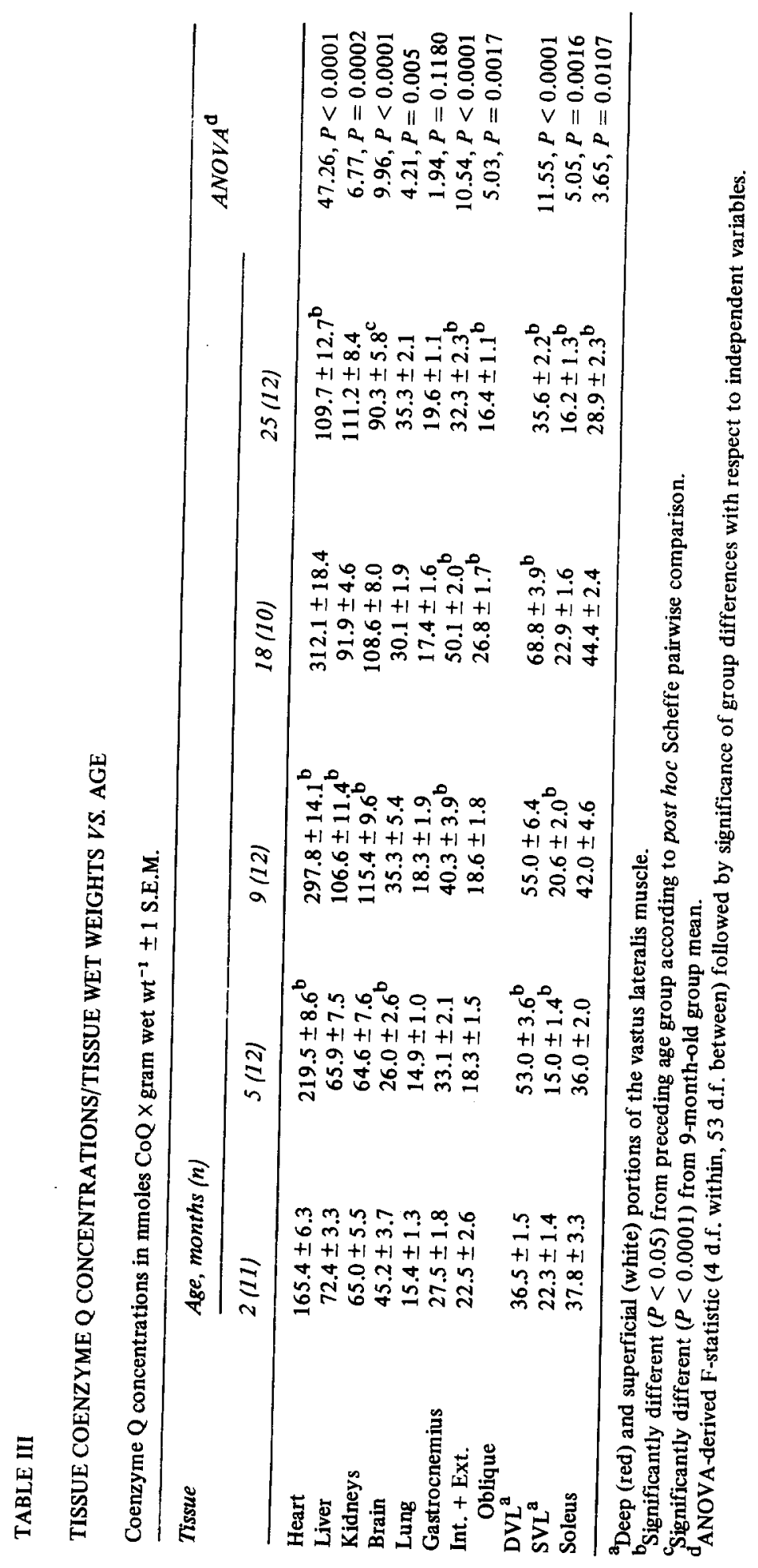




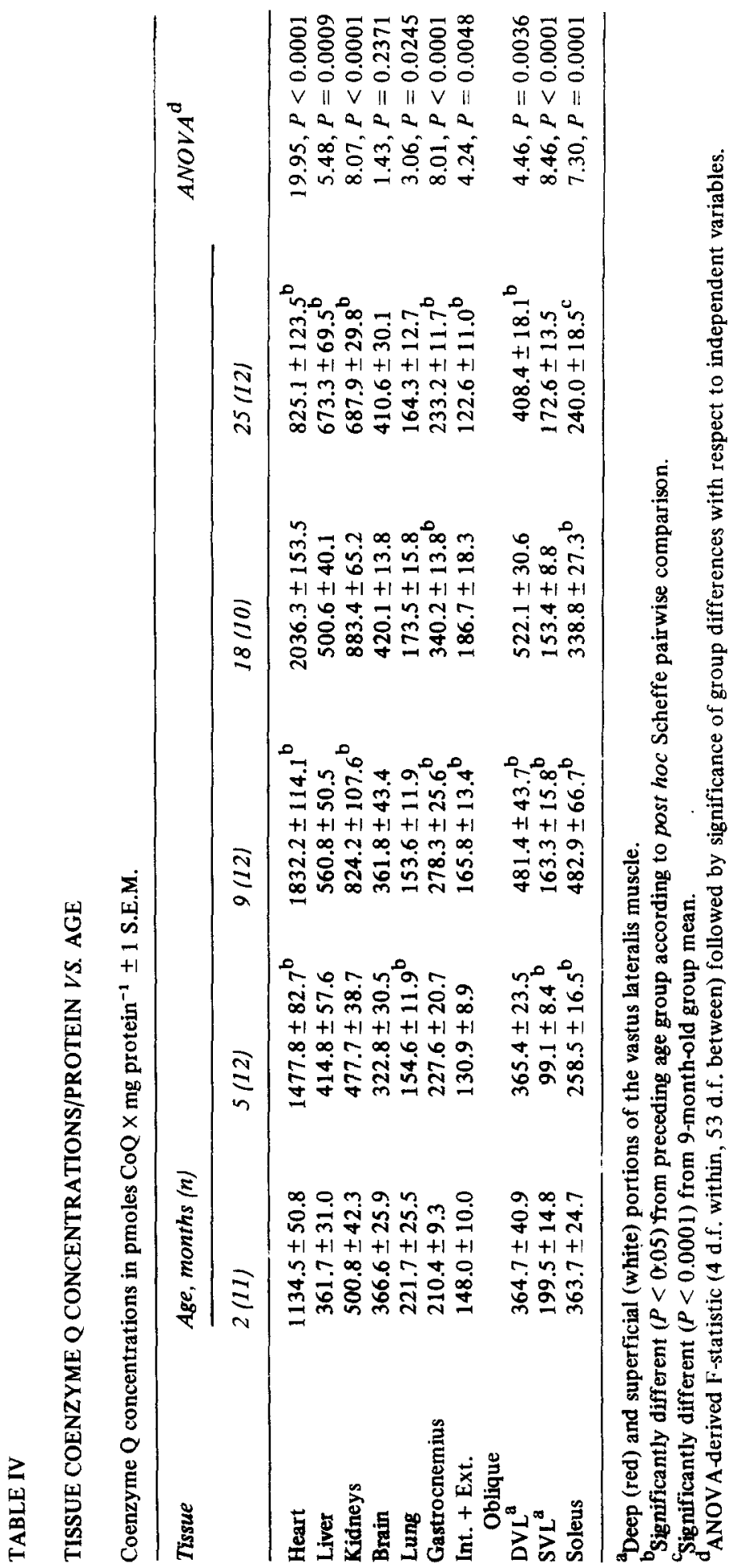




\section{HEART WEIGHT AND COQ CONTENT VS AGE}

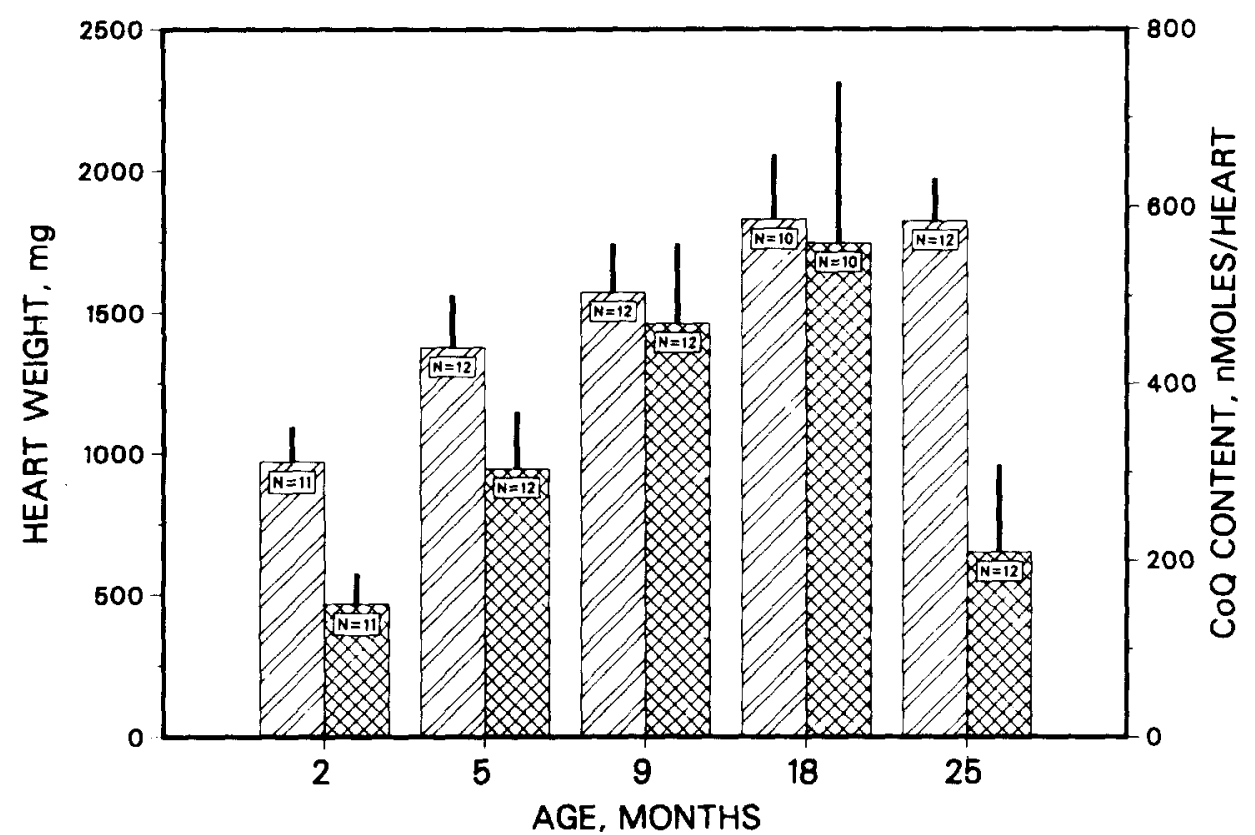

Fig. 2. Heart weight and coenzyme $Q$ content vs. age. $N=$ number of animals in each group. Striped bars represent heart weight. Cross-hatched bars represent coenzyme $Q$ content. Solid bars represent 1 standard deviation.

the several tissues reflect their general oxidative capacities with cardiac tissue highest and the lung and white muscles (oblique, superficial vastus lateralis) lowest [40].

The changes in coenzyme $Q$ content of hearts are compared to changes in heart weight from 2 to 25 months of age in Fig. 2. The loss of coenzyme $Q$ between 18 and 25 months as compared to heart weight is substantial and statistically significant $(P<0.001)$. The decreases in coenzyme $Q$ in the heart between 18 and 25 months is greater than at any other period of the life of these animals.

\section{DISCUSSION}

An appreciation of the importance of quinones in biological energy transfer systems has become evident since the isolation of Köfler's quinone (plastoquinone) [41] and the isolation of coenzyme $Q$ and the discovery of its essential role in the mitochondrial electron transfer chain [11]. The physico-chemical properties and membrane functions of coenzyme $Q$ currently are the subjects of intense study $[42,43]$. Manipulations of the intact animal which affect changes in overall respiratory metabolism are reflected in parallel changes in tissue coenzyme $Q$ concentrations $[44,45]$. In addition, it has been shown 
that coenzyme $\mathrm{Q}$ and cytochrome $c$ concentrations increase significantly in cardiac, gastrocnemius and deep aspect (red) vastus lateralis muscles as a result of forced treadmill endurance training [40]. Such information on coenzyme $Q$, together with reports that oxidoreductases and transferases, enzymes of energy metabolism, decline in activity with age [46], suggests that similar changes might occur in tissue coenzyme $Q$ levels. As the data in Table III and IV indicate, coenzyme $Q$ concentrations of several tissues are influenced significantly by the ageing process.

Cardiac tissue contains the highest tissue concentration of coenzyme $Q$ until the rat reaches 25 months. In the aged rat, the concentration of coenzyme $Q$ in liver, which continues to increase over the life span, surpasses that of the heart. The coenzyme $Q$ concentration of the heart shows a significant decline in the transition from middle age (18 months) to the aged ( 25 months) animal. This dramatic decline in coenzyme $Q$ in the aged heart is illustrated in Fig. 2 in which the changes in heart weight and coenzyme $Q$ content of the whole heart are compared over the life span of the rat. A decease in heart coenzyme $Q$ with age has also been reported by Pignatti et al. [33]. The data in Tables III and IV also show a similar age-related pattern of coenzyme $Q$ concentration changes in the other high oxidative tissues sensitive to oxygen deprivation such as kidney, and the red or mixed oxidative muscles, the gastrocnemius, deep aspect vastus lateralis and soleus. As we have reported previously $[34,40,44,45]$, brain coenzyme $Q$ tends to remain constant under a variety of environmental conditions, including ageing (Tables III and IV). We cannot explain the high coenzyme $Q$ level in the brain of the 2-month-old rat reported in Table III. This is not seen when coenzyme $Q$ concentration is calculated on a mg protein basis.

The changes in coenzyme $Q$ reported herein which are of inherent interest to the field of ageing research, take on additional significance in view of clinical research in the human. Based on the finding that $97 \%$ of injected coenzyme $Q_{10}$ is transferred intact to the inner membrane of heart mitochondria in rats [47], coenzyme $Q$ has been employed effectively in the therapy of a large number of conditions such as congestive heart failure, ischemic kidney and brain disease, endotoxin shock, side effects of antineoplastic agents, and other states which qualify for the category of diseases of energy metabolism [cf. 4850]. With respect to the aged animal, Bliznakov [51] has reported that the administration of coenzyme $Q$ restores the humoral, hemolytic, primary immune response in aged mice and thereby increases the rate of survival. It should be noted that coenzyme $Q$ concentrations in these aged mice were not determined; instead, coenzyme $Q$ deficiency was inferred from decreased rates of reduction of 2,6-dichlorophenol indophenol by succinate catalyzed by homogenates of thymus tissue [51-53]. It is not clear that this assay is specific for coenzyme $Q$ concentration in aged animals in whom flavin, a succinate dehydrogenase prosthetic group, also declines in concentration [6]. Coenzyme $Q$ is under investigation as a therapeutic agent in the treatment of human senile dementias of the Alzheimer's type [54].

The tissue coenzyme $Q$ concentration changes reported herein may have relevance to two of the current theories of cellular aging, the "Free Radical Theory" [55] and the 
"Membrane Hypothesis" [56] as well as to the concepts on the key role of mitochondria in ageing $[57,58]$. The concentration of coenzyme $Q$ in the mammalian inner mitochondrial membrane exceeds that of all other intramembrane components of the electron transfer chain; the ratio of coenzyme $Q$ to cytochrome $c_{1}$ is 19 [59]. It has been suggested that coenzyme $Q$ may serve as a potent antioxidant of lipid peroxidation and superoxide radical formation in addition to its roles in the regulation of complexes $I, I I$ and III, as an electron transfer chain component, and its protonmotive function $[40,60,61]$. The electron transfer chain is a major source of free radicals [62-64], and there is a possibility that coenzyme $Q$ may serve as a free radical quencher. Thus, the high concentrations of coenzyme $Q$ in the inner mitochondrial membrane may have been selected during molecular evolution as a free radical quencher, in addition to its several other functions, at the site of free radical formation [61]. This would also help to explain the seemingly large molar excess of coenzyme $Q$ to other electron transfer components. However, it has been suggested that coenzyme $Q$ serves as a source of free radical pathology during ischemic episodes [65] and that the coenzyme $Q$ semiquinone may give rise to the superoxide radical $\mathrm{O}_{2}^{\bar{\alpha}}$ via autooxidation [66]. Cutler [67] has identified coenzyme $\mathrm{Q}$ as having "longevity determining potential".

An alteration in the concentration of coenzyme $Q$ in the inner mitochondrial membrane, whether due to pathology or ageing, would be expected to result in a kinetic alteration of the functional capacity of that membrane specifically and cell function in general. For example, Vorbeck et al. [68] have reported changes in lipid structural order parameter in hepatic mitochondria with ageing. Such changes in the structure of mitochondrial membranes and its control of coenzyme $Q$ could affect the ionic balance of cellular compartments and thus bear on the "Membrane Hypothesis" of ageing [56].

Finally, it should be noted that rats of 25 months trained in endurance exercise have muscle myoglobin [7], flavin, and mitochondrial concentrations, as well as oxidative enzyme capacities [6], equivalent to that of sedentary rats less than one third their age. In addition, rats maintained on a daily swimming regimen from 6 months to 24 months did not show the decline in enzymes of energy metabolism [69] typical of aged sedentary animals. Reports have also appeared suggesting an increase of longevity in animals [70,71], including humans [72,73], as a result of exercise. Consequently, the appropriateness of the sedentary control animal in ageing research must be questioned. In the use of animal models, as in the present study, the rats are individually confined to a small box with food available ad libidum and no opportunity to express an apparently natural tendency to exercise $[40,71,74]$. In such studies, including the present one, consideration might be given to the strong possibility that declines in enzymes and chemical components of respiratory metabolism correlated with ageing are premature and not a normal part of the ageing process in the free-living animal until a short period prior to death. This strongly implies that the "ageing curve" of the active animal is more rectilinear than that of the sedentary animal. 


\section{ACKNOWLEDGEMENT}

This research received financial support from the American Heart Association of Michigan and The University of Michigan Honors Council Cutcheon Fund. We thank Kenneth Guire for help with the statistical analyses and Robert Blue for advice in the use of the Tellagraf Program (Issco Graphics, San Diego, CA) in the preparation of graphics. We also are grateful to Ms. Margaret Madouse for skillful preparation of the manuscript and Dr. Kathleen Timberlake for her captious perusal of the manuscript.

\section{REFERENCES}

1 D.R. Sanadi, Metabolic changes and their significance in aging. In C.F. Finch and L. Hayflick (eds.), Handbook of the Biology of Aging, Van Nostand-Reinhold, New York, 1977, pp. 73-98.

2 R.G. Hansford, Energy metabolism. In J.R. Florini (ed.), CRC Handbook of Biochemistry of Aging. CRC Press, Boca Raton, 1981, pp. 137-162.

3 E.C. Weinbach and J. Garbus, Oxidative phosphorylation in mitochondria from aged rats. J. Biol. Chem, 234 (1959) 412-417.

4 R.G. Hansford, Lipid oxidation by heart mitochondria from young adult and senescent rats. Biochem. J., 170 (1978) 285-295.

5 R.G. Hansford and F. Castro, Age-linked changes in the activity of enzymes of the tricarboxylate cycle and lipid oxidation, and of carnitine content, in muscles of the rat. Mech. Ageing Dev., 19 (1982) 191-201.

6 R.E. Beyer, J.W. Starnes, D.W. Edington, R.J. Lipton, R.T. Compton and M.A. Kwasman, Exerciseinduced reversal of age-related declines of oxidative reactions, mitochondrial yield, and flavins in skeletal muscle of the rat. Mech. Ageing Dev., 24 (1984) 309-323.

7 R.E. Beyer and J.E. Fattore, The influence of age and endurance exercise on the myoblogin concentration of skeletal muscle of the rat. J. Gerontol., 39 (1984) 525-530.

8 G.M. Abu-Erreish, H. Wohlrab and D.R. Sanadi, In vitro and in vivo changes in mitochondria from hearts of senescent rats. Fed. Proc., 33 (1974) 1518.

9 J.W. Starnes, R.E. Beyer and D.W. Edington, Myocardial adaptations to endurance exercise in aged rats. Am. J. Physiol., 245 (Heart Circ. Physiol., 14) (1983) H560-H566.

10 J.W. Starnes, D.W. Edington and R.E. Beyer, Myocardial protein synthesis during aging and endurance exercise in rats. J. Gerontol., 38 (1983) 660-665.

11 F.L. Crane, Y. Hatefi, R.L. Lester and C. Widmer, Isolation of a quinone from beef heart mitochondria. Biochim. Biophys. Acta, 25 (1957) 220-221.

12 E. Rossi, B. Norling, B. Persson and L. Ernster, Studies with ubiquinone-depleted submitochondrial particles. Effect of extraction and reincorporation of ubiquinone on the kinetics of succinate dehydrogenase. Eur. J. Biochem., 16 (1970) 508-513.

13 M. Gutman, E.B. Kearney and T.P. Singer, Regulation of succinate dehydrogenase activity by reduced coenzyme $Q_{10}$. Biochemistry, 10 (1971) 2726-2732.

14 M. Gutman, E.B. Kearney and T.P. Singer, Control of succinate dehydrogenase in mitochondria. Biochemistry, 10 (1971) 4763-4770.

$15 \mathrm{M}$. Gutman and N. Silman, The steady state activity of succinate dehydrogenase in the presence of opposing effectors $\mathrm{I}$. The effect of L-malate and coenzyme $\mathrm{QH}_{2}$ on the enzymic activity. Mol. Cell. Biochem., 7 (1974) 51-58.

16 M. Gutman, C.J. Coles, T.P. Singer and J.E. Casida, On the functional organization of the respiratory chain at the dehydrogenase-coenzyme Q junction. Biochemistry, 10 (1971) 2036-2043.

17 E. Glazek, B. Norling and L. Ernster, Activation of NADH oxidase by succinate in partially ubiquinone-depleted submitochondrial particles. FEBS Lett., 46 (1974) 123-126. 
18 L. Ernster, I.-Y. Lee, B. Norling and B. Persson, Studies with ubiquinone-depleted sabmitochondrial particles. Essentiality of ubiquinone for the interaction of succinate dehydrogenase, NADH dehydrogenase, and cytochrome b. Eur. J. Biochem., 9 (1969) 299-310.

19 B.D. Nelson, B. Norling, B. Persson and L. Ernster, Effect of thenoyltrifluoroacetone on the interaction of succinate dehydrogenase and cytochrome $b$ in ubiquinone-depleted submitochondrial particles. Biochem. Biophys. Res. Commun., 44 (1971) 1312-1329.

20 B.D. Nelson, B. Norling, B. Persson and L. Ernster, Influence of ubiquinone on the rate of antimycin binding to submitochondrial particles. Biochim. Biophys. Acta, 267 (1972) 205-210.

21 P. Mitchell, Protonmotive redox mechanism of the cytochrome $b-c_{1}$ complex in the respiratory chain: Protonmotive ubiquinone cycle. FEBS Lett., S6 (1975) 1-6.

22 P. Mitchell, The protonmotive Q cycle: A general formulation. FEBS Lett., 59 (1975) 137-139.

23 P. Mitchell and J. Moyle, Protonmotive mechanisms of quinone function. In B.L. Trumpower (ed.), Functions of Quinones in Energy Conserving Systems, Academic Press, New York, 1982, pp. 553-575.

24 R.A. Morton, G.M. Wilson, J.S. Lowe and W.M.F. Leat, Ubiquinone, Chem. Ind., 1649 (1957).

25 R.A. Morton, Isolation and characterization of ubiquinone (coenzyme Q) and ubichromenol. In G.E.W. Westenholme and C.M. O'Connor (eds.), Quinones in Electron Transport, Little Brown, Boston, 1961, pp. 5-25.

26 D.H.L. Bishop, K.P. Pandya and H.K. King, Ubiquinone and vitamin K in bacteria. Biochem. J., 83 (1962) 606-614.

27 F.L. Crane, Distribution of quinones. In R.A. Morton (ed.), Biochemistry of Quinones, Academic Press, London, 1965, pp. 183-206.

28 R.K. Thauer, K. Jungerman and K. Decker, Energy conservation in chemotrophic anaerobic bacteria. Bacteriol Rev., 41 (1977) 100-180.

29 D.E. Green, Structure-function interrelationships in mitochondrial electron transport and oxidative phosphorylation. Discuss Faraday Soc., 27 (1959) 206-216.

30 T.E. King, Ubiquinone proteins in cardiac mitochondria. In B.L. Trumpower (ed.), Function of Quinones in Energy Conserving Systems. Academic Press, New York, 1982, pp. 3-25.

$31 \mathrm{C} . \mathrm{A}$. Yu and $\mathrm{L}$. Yu, Identification of ubiquinone binding proteins in ubiquinol-cytochrome $c$ reductase by arylazido ubiquinone derivative. Biochem. Biophys. Res. Commun., 96 (1980) 286292.

32 C.A. Yu and $\mathrm{L}$. Yu, Interaction between succinate dehydrogenase and ubiquinone-binding protein from succinate-ubiquinone reductase. Biochim. Biophys. Acta, 593 (1980) 24-38.

33 C. Pignatti, $M$. Cocchi and $H$. Weiss, Coenzyme $Q_{10}$ levels in rat heart of different age. Biochem. Exp. Biol., 16 (1980) 39-42.

34 R.E. Beyer, B. Ramp, S. Rhee, K. Kreitman and M. Stein, Tissue coenzyme Q concentrations with age and coenzyme $Q$ treatment. The Gerontologist, 23 (1983) 174.

35 R.J. Barnard and J.B. Peter, Effect of exercise on skeletal muscle III. Cytochrome changes. J. Appl. Physiol., 31 (1971) 904-908.

36 R.E. Beyer, A rapid biuret assay for protein of whole fatty tissues. Anal. Biochem., 129 (1983) $483-485$.

37 Y. Kaziro, S. Ochoa, R.C. Warner and J.-Y. Chen, Metabolism of propionic acid in animal tissues VIII. Crystalline propionyl carboxylase. J. Biol. Chem., 236 (1961) 1917-1923.

38 A. Kröger, Determination of contents and redox state of ubiquinone and menaquinone. Methods Enzymol., 53 (1978) 579-591.

39 J.A. Pierce, Biochemistry of aging in the lung. In L. Cauder and J.H. Moyers (eds.), Aging of the Lung, Grune and Stratton, New York, 1964, pp. 61-69.

40 R.E. Beyer, P.G. Morales-Corral, B.J. Ramp, K.R. Kreitman, M.J. Falzon, S.Y.S. Rhee, T.W. Kuhn, M. Stein, M.J. Rosenwasser and K.J. Cartwright, Elevation of tissue coenzyme $Q$ (ubiquinone) and cytochrome $c$ concentrations by endurance exercise in the rat. Arch. Biochem. Biophys., 234 (1984) 323-329.

41 M. Köfler, In Festschrift Emil Christoph Barell, Hoffman-La Roche, Basle, 1946, pp. 199-212.

42 B.L. Trumpower, Function of Quinones in Energy Conserving Systems, Academic Press, New York, 1982. 
43 G. Lenaz, Coenzyme Q: Biochemistry, Bioenergetics and Clinical Applications of Ubiquinone, John Wiley, New York, 1985

44 R.E. Beyer, W.M. Noble and T.J. Hirschfield, Alterations of rat-tissue coenzyme Q (ubiquinone) levels by various treatments. Biochim. Biophys. Acta, 57 (1962) 376-379.

45 R.E. Beyer, W.M. Noble and T.J. Hirschfield, Coenzyme Q (ubiquinone) levels of tissues of rats during acclimation to cold. Can.J. Biochem. Physiol., 40 (1962) 511-518.

46 M.S. Kanungo, Biochemistry of Ageing, Academic Press, London, 1980, pp, 81 - 94.

47 T. Nakamura, H. Sanma, M, Himeno and K. Kato, Transfer of exogenous coenzyme $Q_{10}$ to the inner membrane of heart mitochondria in rats. In Y. Yamamura, K. Folkers and Y. Ito (eds.), Biomedical and Clinical Aspects of Coenzyme $Q$, Vol 2, Elsevier/North Holland, Amsterdam, 1980 , pp. 3-13.

48 K. Folkers and Y. Yamamura (eds.), Biomedical and Clinical Aspects of Coenzyme Q, Vol. 1, Elsevier, Amsterdam, 1977.

49 Y. Yamamura, K. Folkers and Y. Ito (eds.), Biomedical and Clinical Aspects of Coenzyme $Q$, Vol. 2, Elsevier, Amsterdam, 1980.

$50 \mathrm{~K}$. Folkers and Y. Yamamura (eds.), Biomedical and Clinical Aspects of Coenzyme Q. Vol. 3, Elsevier, 1981.

51 E.G. Bliznakov, Suppression of immunological responsiveness in aged mice and interrelationship with coenzyme Q deficiency. Adv. Exp. Biol. Med., 121 (1979) 361-369.

52 E.G. Bliznakov, Immunological senescence in mice and its reversal by coenzyme $\mathrm{Q}_{10}$. Mech. Ageing Dev., 7 (1978) 189-197.

53 E.G. Bliznakow, T. Watanabe, S. Saji and K. Folkers, Coenzyme Q deficiency in aged mice. J. Med., 9 (1978) $337-346$.

54 E. Roberts, Potential therapies in aging and senile dementias. Ann. N.Y. Acad. Sci., 396 (1982) 165-178.

55 D. Harman, Aging: a theory based on free radical and radiation chemistry. J. Gerontol., 11 (1956) 298-300.

56 I. Zs.-Nagy, A membrane hypothesis of aging. J. Theor. Biol., 75 (1978) 189-195.

57 J. Miguel, A.C. Economos, J. Fleming and J.E. Johnson, Jr., Mitochondrial role in cell ageing. Exp. Gerontol., 15 (1980) 575-591.

58 D. Harman, Free radical theory of aging: consequences of mitochondrial aging. Age, 6 (1983) 8694.

59 D.E. Green and D.C. Wharton, Stoichiometry of the fixed oxidation-reduction components of the electron transfer chain of beef heart mitochondria. Biochem., Z., 338 (1963) 335-348.

$60 \mathrm{~K}$. Takeshige, R. Takayanagi and S. Minakami, Reduced coenzyme $Q_{10}$ as an antioxidant of lipid peroxidation in bovine heart mitochondria. In Y. Yamamura, K. Folkers and Y. Ito (eds.), Biochemical and Clinical Aspects of Coenzyme Q, Vol. 2, Elsevier/North Holland, Amsterdam, 1980, pp. 15--25.

61 R.E. Beyer and J.W. Starnes, Coenzyme $Q$ and myocardial function in aging and exercise. In H.L. Stone (ed.), Advances in Myocardiology (Pathobiology of Cardiovascular Injury), Vol. 7, Nijhoff, Hingham, in press.

62 A.K. Schneider, E.E. Smith and F.E. Hunter, Jr. Correlation of oxygen consumption with swelling and lipid peroxide formation when mitochondria are treated with the swelling-inducing agents $\mathrm{Fe}^{2+}$, glutathione, ascorbate, or phosphate. Biochemistry, 3 (1964) 1470-1477.

63 G. Loschen, A. Assi and L. Flohe, Mitochondrial $\mathrm{H}_{2} \mathrm{O}_{2}$ formation; relation with energy conservation. FEBS Lett., 33 (1973) 84-87.

64 B.E. Leibovitz and B.V. Siegel, Aspects of free radical reactions in biological systems: aging. $J$ Gerontol, 35 (1980) 45-56.

65 H.B. Demopoulos and E.S. Flamm, Possible pathology induced by coenzyme $Q_{10}$ In K. Folkers and Y. Yamamura (eds.), Biomedical and Clinical Aspects of Coenzyme Q, Vol. 3, Elsevier/North Holland, Amsterdam, 1981, pp. 373-384.

66 C. Lind, P. Hochstein and L. Ernster, DT-diaphorase as a quinone reductase; A cellular control device against semiquinone superoxide radical formation. Arch. Biochem. Biophys., 216 (1982) 178-185. 
67 R.G. Cutler, Longevity is determined by specific genes: testing the hypothesis. In R.C. Adelman and G.S. Roth (eds.), Testing the Theories of Aging, CRC Press, Boca Raton, 1982, pp. 25-114.

68 M.L. Vorbeck, A.P. Martin, J.W. Long, Jr., J.M. Smith and R.R. Orr, Jr. Age-dependent modification of lipid composition and lipid structural order parameter of hepatic mitochondria. Arch. Biochem. Biophys., 217 (1982) 351-361.

69 J.C. Young, M. Chen and J.O. Holloszy, Maintenance of the adaptation of skeletal muscle mitochondria to exercise in old rats. Med. Sci. Sports Exerc., 15 (1983) 243-246.

70 D.W. Edington, A.C. Cosmas and W.B. McCafferty, Exercise and longevity: evidence for a threshold age. J. Gerontol., 27 (1972) 341-343.

71 C.L. Goodrick, Effect of long-term voluntary wheel exercise on male and female Wistar rats 1. Longevity, body weight, and metabolic rate. Gerontology, 26 (1980) 22-33.

72 S.N. Blair, N.N. Goodyear, L.W. Gibbons and K.H. Cooper, Physical fitness and incidence of hypertension in healthy normotensive men and women. J. Am. Med. Assoc., 252 (1984) 487-490.

73 R.S. Paffenbarger, Jr., R.T. Hyde, A.L. Wing and C.H. Steinmetz, A natural history of athleticism and cardiovascular health. J. Am. Med. Assoc., 252 (1984) 491-495.

$74 \mathrm{~J} . \mathrm{R}$. Slonaker, The normal activity of the albino rat from birth to natural death, its rate of growth and the duration of life. J. Anim. Behav., 2 (1912) 20-42. 